\title{
Configurações
}

Revista de sociologia

$10 \mid 2012$

Políticas Públicas

\section{Políticas públicas para o emprego em Portugal: de ação reguladora a potencial emancipatório?}

Public policies for employment in Portugal: from regulatory action to emancipatory potential?

Les politiques publiques de l'emploi au Portugal: des mesures réglementaires a potentiel émancipateur?

\section{Carla Valadas}

\section{(2) OpenEdition}

\section{Journals}

Edição electrónica

URL: http://journals.openedition.org/configuracoes/1521

DOI: 10.4000/configuracoes. 1521

ISSN: 2182-7419

\section{Editora}

Centro de Investigação em Ciências Sociais

\section{Edição impressa}

Data de publição: 1 Dezembro 2012

Paginação: 83-94

ISBN: 1646-5075

ISSN: 1646-5075

\section{Refêrencia eletrónica}

Carla Valadas, « Políticas públicas para o emprego em Portugal: de ação reguladora a potencial emancipatório? », Configurações [Online], 10 | 2012, posto online no dia 17 fevereiro 2014, consultado o 19 abril 2019. URL : http://journals.openedition.org/configuracoes/1521 ; DOI : 10.4000/ configuracoes. 1521

Este documento foi criado de forma automática no dia 19 Abril 2019. 


\title{
Políticas públicas para o emprego em Portugal: de ação reguladora a potencial emancipatório?
}

\author{
Public policies for employment in Portugal: from regulatory action to \\ emancipatory potential? \\ Les politiques publiques de l'emploi au Portugal: des mesures réglementaires a \\ potentiel émancipateur?
}

Carla Valadas

1 Desde o início do novo milénio temos assistido, em Portugal, a um aumento contínuo da taxa de desemprego e a uma precarização das relações e condições de trabalho. 0 desemprego massivo, tanto de longa duração (DLD), como o desemprego jovem constituem-se em desafio para os governantes portugueses que, em particular desde o início do novo milénio ${ }^{1}$, têm desenvolvido um conjunto de políticas destinadas a minorar os impactos negativos do desemprego, mas, sobretudo, a incentivar a (re)entrada no mercado de trabalho de grupos sociais em situação de maior vulnerabilidade (e.g. os DLD, os jovens). Estas medidas inserem-se numa estratégia definida a nível europeu, no final dos anos noventa do século passado, designada Estratégia Europeia de Emprego (EEE). Na nossa perspetiva, a EEE representa uma nova abordagem do que deve ser o papel do Estado e transporta consigo um modelo de funcionamento e organização dos mercados de trabalho a nível europeu com contornos muito específicos.

Brevemente, recordamos que a EEE foi delineada num contexto político e económico em que o desemprego constituía uma preocupação em muitos Estados-membros, e em que as preocupações sociais se associavam aos objetivos primordiais do projeto de construção europeia, ancorados na promoção de um maior crescimento económico e no reforço da competitividade ${ }^{2}$. De entre um conjunto de orientações, comuns aos diversos países, que estes escolhiam adotar e adaptar em função das suas características internas, pretendiase incentivar a participação dos trabalhadores no mercado de trabalho, promovendo a sua 
empregabilidade através de uma abordagem preventiva e "ativa" ${ }^{3}$ em detrimento das (tradicionais) "políticas passivas" (e.g. compensações em caso de desemprego; pensões de reforma antecipadas). Como recordam, entre outros autores, Ferrera e Sacchi (2005) colocar a ênfase na prevenção e nas políticas ativas ${ }^{4}$ de emprego - que a EEE ajudou a disseminar - e inspira-se em paradigmas e valores dominantes nas políticas anglosaxónicas e do Norte da Europa ${ }^{5}$. A centralidade atribuída a estas políticas representa um dos mais importantes desenvolvimentos no que diz respeito ao funcionamento dos mercados de trabalho e às políticas de bem-estar europeias desde meados dos anos noventa (Mailand, 2005).

3 A noção de ativação pode ser compreendida a partir de múltiplas dimensões que se entrecruzam. Seguindo de perto o esquema analítico proposto por Amparo Serrano Pascual (2003), estamos, simultaneamente, perante um método que pressupõe uma forma específica de encorajar os indivíduos a trabalhar/ inserindo-se no mercado de trabalho, ao qual se associam objetivos específicos. De entre estes destaca-se o aumento da taxa de atividade e o combate à exclusão social associada, designadamente, ao DLD. Pode também a ideia de "ativação" estar ligada a um projeto (europeu) que consiste, neste caso, em adaptar os sistemas nacionais aos desafios associados aos novos modos de produção, em que deverá ancorar-se um modelo de sociedade assente no conhecimento. Finalmente, estamos também perante uma ideologia que transporta consigo alterações na conceção e representação da cidadania, do desemprego, da perceção do risco e que simboliza, por detrás de todos estes fatores, uma nova forma de pensar e implementar as funções do Estado, enquanto garante do bem-estar social.

Centremo-nos nas mudanças associadas a uma nova forma de conceber os direitos sociais e a um novo modo de intervenção do Estado. Em sociedades marcadas pela incerteza e pelo risco, torna-se necessário dotar os indivíduos dos instrumentos necessários para a gestão dos riscos. O Estado deve assegurar os mecanismos que permitam uma adaptação rápida aos novos desafios com que os indivíduos são confrontados, inevitavelmente, ao longo da sua vida. Ou seja, sobre estes passa a recair a responsabilidade pelo seu próprio sucesso no que toca a sua integração no mercado de trabalho. Parafraseando Bourdieu, o indivíduo passa a ser considerado "o único responsável pela sua própria desgraça", cabendo-lhe procurar a "self help" (Bourdieu, 1998: 10). A individualização do risco implica que o desemprego seja concebido como uma situação perante a qual o indivíduo é responsável. Este tipo de ideias integram uma abordagem das políticas sociais influenciada pelos ideais e teorias liberais ${ }^{6}$ que, desde há algum tempo, atravessam a generalidade dos sistemas de bem-estar social europeus. Apesar das diferenças que podemos encontrar na sua aplicação em resultado dos diferentes contextos nacionais, isto é, das respetivas condições institucionais, tradições históricas e legais, temos vindo a assistir, sobretudo desde a década de noventa do século passado, à transferência das responsabilidades do Estado no domínio da proteção social para o setor privado e também para as famílias e a sociedade civil, num sentido mais amplo.

5 Estas orientações foram, na nossa perspetiva, claramente incorporadas na EEE. Porém, ao longo da sua implementação, podemos delimitar diferentes fases. Uma primeira fase, entre os anos de 1997 e 2003 foi marcada pela definição de metas políticas ambiciosas (e.g. alcançar o pleno emprego; promover a qualidade do emprego), numa altura em que, pela primeira vez na história da UE, o (des)emprego passou a ser encarado como um tema de interesse comum na agenda política dos vários Estados-membros. Foi sobretudo durante este período que a ênfase nas políticas ativas de emprego e a prevenção do desemprego, 
em particular dos jovens e dos adultos, se evidenciaram como os dois domínios de intervenção privilegiados. Numa segunda fase, assistimos a uma perda de especificidade e detalhe na formulação dos objetivos e prioridades ao nível das políticas de emprego e também a uma menor capacidade de monitorização e coordenação das mesmas por parte da $\mathrm{CE}^{7}$. Este período é determinado em larga medida pelo processo que conduziu à revisão da Estratégia de Lisboa no ano de 2005. A partir de 2008, os efeitos negativos decorrentes da crise económica e financeira que atingiu os países da UE e também os EUA e a que estiveram associadas, entre outras consequências, a desaceleração do crescimento económico, o aumento massivo do desemprego e o aumento dos défices públicos nacionais, revelaram a capacidade reduzida de os países da UE enfrentarem uma conjuntura económica internacionalmente adversa. Desde essa altura, a consolidação de regimes políticos de centro direita na generalidade dos países europeus, o agravamento das condições financeiras e económicas de muitos países, alguns dos quais - como é o caso de Portugal - tiveram, inclusivamente, de receber auxílio financeiro externo por parte de organizações internacionais (e.g. CE, FMI e BCE), determinou que as políticas de emprego, nomeadamente, passassem a ser delineadas sob um clima de austeridade. Este novo contexto obriga à redução das despesas sociais do Estado e determina a reconstituição do papel exercido pelo Estado, cujas responsabilidades e funções regulatórias no domínio da proteção social e enquanto garante do bem-estar enfraquecem. Para além das especificidades que, como vimos, marcam estes diferentes períodos, consideramos que, mesmo no período (inicial) de maior crescimento económico, em que a maioria dos países da UE não apresentava taxas de desemprego elevadas, a prioridade em torno da flexibilização dos mercados de trabalho europeus surgia claramente destacada. 0 princípio de tornar os mercados de trabalho e, em particular, a mão de obra mais flexível, maleável, adaptável era encarada como um desígnio central de modo a alcançar os objetivos económicos (e.g. controle dos défices públicos e baixos níveis de inflação) privilegiados no âmbito da consolidação do mercado único. Neste sentido, consideramos que, apesar das "boas intenções" que alguns Estados-membros, ou, mais concretamente, alguns protagonistas políticos como é o caso de Jacques Delors, procuraram realçar de forma mais vincada num certo momento da trajetória da EEE e/ou da própria UE, a dimensão social do projeto europeu permaneceu sempre numa posição subordinada (Valadas, 2012: 187). O poder emancipatório que poderíamos atribuir às políticas de emprego, por via, nomeadamente, de uma abordagem mais "ativa", participada, envolvida, responsabilizadora não só acabaria por não se concretizar como podemos, inclusive, questionar se terá sido algum dia efetivamente partilhado e transposto para as diferentes realidades nacionais.

6 Vejamos, no ponto seguinte, em que medida as políticas de emprego recentemente adotadas pelo Estado português transportam consigo as orientações decorrentes da EEE e incorporam, de uma forma mais abrangente, os pressupostos e os ideais liberais que perpassam, nos nossos dias, a generalidade das políticas sociais europeias. No âmbito do presente artigo, olhamos com especial atenção para as implicações daí decorrentes no que toca a produção de novas formas de desigualdade. Consideramos que existem duas direções possíveis para podermos apreender as alterações na ação regulatória exercida pelo Estado no domínio das políticas de emprego. A primeira decorre de uma análise exaustiva da legislação existente, no sentido de apreendermos quais os objetivos das políticas e as alterações recentes ao nível dos princípios ideológicos e das prioridades da ação política. A segunda via consiste em examinar o modo como as (novas) orientações e prioridades da agenda política são transpostas para as práticas administrativas e/ou o 
funcionamento dos serviços, i.e. para o modo como as políticas são implementadas. Apesar de o desenvolvimento exaustivo e detalhado destas linhas de análise não caber nos objetivos deste texto ${ }^{8}$, em seguida apresentamos algumas reflexões que resultam do entrecruzamento de ideias que decorre de uma análise ao nível dos princípios e das orientações políticas e também de alterações significativas ao nível das práticas administrativas e dos procedimentos (e.g. por parte do Serviço Público de Emprego) que têm vindo a ser adotadas no caso português.

\section{Mudanças nos objetivos e no conteúdo das políticas}

7 Em Portugal, as políticas ativas de emprego são um elemento relativamente recente, em comparação com outros países da UE9. A implementação da EEE veio influenciar o discurso oficial e político em torno da necessidade de reforçar as políticas ativas de emprego. Está em causa a adoção de uma forma de intervenção com contornos distintos dos que vigoravam no passado ${ }^{10}$ que coloca a ênfase no indivíduo e na promoção da sua empregabilidade ${ }^{11}$. Este tipo de estratégia implica pôr em prática medidas destinadas a reforçar os incentivos para que os indivíduos se insiram ${ }^{12}$ rapidamente no mercado de trabalho e visa também reforçar as medidas destinadas a promover a aprendizagem ao longo da vida, com o objetivo de melhorar os níveis de formação e qualificação dos trabalhadores.

Para que estes objetivos possam ser concretizados, é necessário alterar a forma de proceder dos Serviços Públicos de Emprego (SPE). Em Portugal, o Instituto de Emprego e Formação Profissional (IEFP) desempenha um papel decisivo na implementação de um conjunto de políticas públicas (e.g. programas de estágio que visam promover a inserção de jovens no mercado de trabalho; Programas Ocupacionais) que têm um impacto determinante na gestão e no controlo dos movimentos de emprego. O IEFP tem também um papel importante no domínio da formação profissional. O modo de funcionamento desta instituição alterou-se em função das novas prioridades das políticas de emprego nacionais ${ }^{13}$, com implicações ao nível da própria organização interna dos serviços, com reflexos no tipo de atendimento prestado aos desempregados e/ou trabalhadores à procura de um novo emprego. No âmbito de um processo de modernização e revisão das práticas em que tem lugar a substituição de um "perfil" eminentemente passivo dos desempregados, de meros recetores de pedidos de emprego e/ou de beneficiários de prestações de desemprego, para um "perfil" mais ativo, os SPE são chamados a implementar uma abordagem preventiva, empreendedora e ativa. Ou seja, cabe-lhes dirigir a sua atuação e as suas prioridades para a prevenção, desde logo, de uma eventual situação de desemprego, assegurando que os indivíduos sejam "equipados" com as competências e/ou habilitações que lhes permitam encontrar um emprego alternativo (Gallie, 2004). Os SPE devem prosseguir uma estratégia personalizada e de proximidade que contribua para corresponsabilizar os indivíduos (e.g. desempregados) num processo permanente de (re)adequação das suas capacidades e recursos (e.g. qualificações) às necessidades do mercado de trabalho.

Estamos perante uma nova dinâmica, cujo enfoque é a pró-atividade dos próprios candidatos a um (novo) emprego. Ora, numa altura em que assistimos a um aumento massivo do desemprego, esta nova forma de abordagem e intervenção junto dos desempregados pressupõe uma pressão acrescida sobre o SPE. Numa conjuntura particularmente desfavorável ${ }^{14}$, em que as respostas deveriam ser mais eficazes, 
reconhece-se que os Centros de Emprego, em concreto, lidam com limitações acrescidas relacionadas com a falta de recursos humanos e uma real incapacidade em encontrar formas inovadoras de responder às necessidades do mercado de trabalho ${ }^{15}$. Deste modo, realçam-se as descoincidências entre o aumento muito significativo das necessidades sociais e a efetiva capacidade de resposta por parte dos serviços do Estado. As fragilidades que os caracterizam, em lugar de serem ultrapassadas, são antes instrumentalizadas e colocadas ao serviço de orientações políticas e económicas marcadas pela contenção de custos e pela privatização dos próprios serviços, no limite pela desresponsabilização (das suas obrigações) e residualização da intervenção do Estado no domínio da proteção social.

10 As marcas deste modelo liberal, orientado pelas lógicas da ativação, da flexibilização, da individualização, estendem-se também à legislação existente ${ }^{16}$. Neste domínio, temos vindo a assistir a restrições nos critérios de elegibilidade, a diminuições nas comparticipações financeiras em caso de despedimento e também nos montantes e duração dos subsídios de desemprego. Sublinhe-se que estas restrições afetam, com especial intensidade, certos grupos sociais em situação de maior fragilidade, como é o caso dos jovens, das mulheres, dos trabalhadores mais idosos, dos imigrantes, dos deficientes e os que se encontram numa condição, frequentemente transversal a todos, os trabalhadores com vínculos laborais precários.

11 Do que dissemos acima, resulta a ideia de que, para além do slogan político ${ }^{17}$ que persegue o ideal de que é imprescindível colocar mais pessoas no mercado de trabalho, criando mais e melhores empregos, assistimos, de facto, a uma fragilização da intervenção do Estado no domínio da proteção social. Está em causa um novo modo de intervenção do Estado orientado para a salvaguarda dos interesses económicos e a promoção da competitividade, em detrimento das preocupações em torno da coesão social e da promoção do bem-estar social.

\section{0 caráter mais profundo e a extensão das desigualdades sociais}

12 Numa sociedade como é a sociedade portuguesa, profundamente marcada por défices de qualificação e produtividade bastante consideráveis, a prossecução de medidas que permitam aos trabalhadores melhorar a sua capacidade de adaptação a uma sociedade cada vez mais tecnológica e caracterizada por mudanças rápidas, constitui um desafio, mas representa também um conjunto de oportunidades com um forte poder emancipatório. Em termos concretos, estas têm sido aproveitadas diferentemente por pessoas ligadas a diferentes setores de atividade, com diferentes vínculos laborais e níveis de qualificação. Por um lado, temos exemplos de sucesso (mesmo em setores mais tradicionais como é o caso do têxtil e do calçado) no que toca a capacidade de criação de conhecimento e inovação, liderados por um conjunto restrito de trabalhadoresempreendedores que conjugam de forma eficaz saber, criatividade, risco e abertura. Por outro lado, temos uma multiplicidade de situações em que o poder emancipatório de muitos programas e medidas (e.g. destinados a melhorar as qualificações e a estimular a empregabilidade e até a autoestima dos trabalhadores) não é mobilizado, nem ajuda a fortalecer o acesso à (plena) cidadania. Em suma, estamos perante o reforço da dualização/segmentação do mercado de trabalho que marca, desde há muito, o dia a dia das empresas e de muitos trabalhadores portugueses. 
Como demonstrámos num trabalho de investigação recente (Valadas, 2012), tem vindo a agravar-se o fosso entre aqueles - uma minoria - que têm acesso a condições de aprendizagem, formação, trabalho (em alguns casos flexíveis) generosas e que lhes proporcionam um elevado nível de segurança e bem-estar e o grupo, alargado, dos indivíduos, cujos níveis de formação e qualificação são baixos e incipientes e cujos trajetos profissionais são marcados pela precariedade (e.g. remuneratória, laboral) e incerteza. Estas diferenças resultam de "distribuições desiguais de recursos ou do controle desigual de meios de ação" de entre os quais se destaca, designadamente, o trabalho qualificado e organizado e também as instituições de vinculação social como é caso das redes de parentesco (Costa, 2012: 12). Socorrendo-se do esquema analítico proposto por Charles Tilly (2005) para abordar e enquadrar o tema das desigualdades globais, António Firmino da Costa (2012) identifica alguns mecanismos que, na nossa perspetiva, são particularmente relevantes para entendermos os diferentes níveis de acesso e alguns dos fatores centrais que estão na base das desigualdades que acima abordámos. Referimo-nos em concreto à posse, acesso e controle desiguais de capital financeiro e de informação, dos media e do conhecimento científico-tecnológico. Estes determinam que, para alguns grupos de indivíduos (a larga maioria dos trabalhadores portugueses como defendemos neste artigo) o surgimento e o aproveitamento de novas oportunidades e o ultrapassar de certas "barreiras" sociais se tornem bastante limitadores.

$\mathrm{Na}$ sociedade portuguesa, persistem e agravam-se as condições económicas (e.g. distribuição desigual de rendimentos), culturais, educacionais contrastantes de que partem os indivíduos ${ }^{18}$. De igual modo, as diferentes posições e/ou dos por mecanismos de proteção social mais robustos e distribuídos de forma equitativa podem configurar novas e preocupantes formas de rutura dos laços sociais. Num contexto económico, político e também social em que o Estado (representado pelas instâncias governamentais que maioritariamente formulam e executam as políticas econômicas e sociais) chama a si a tarefa de promover a empregabilidade (e não o emprego) para todos, e sobretudo opta por não proporcionar condições de integração no mercado de trabalho que permitam aos indivíduos satisfazer as suas necessidades (mais) básicas, nem tão pouco alcançar a sua realização social e profissional ${ }^{19}$, emergem (novas) patologias e reforçam-se as condições de anomia de que há mais de um século atrás eram denunciadas por Émile Durkheim (1893).

\section{BIBLIOGRAPHY}

BARBIER, J.-C. (2005), “The European Employment Strategy, a Channel for Activating Social Protection?, in J. Zeitlin, P. Pochet e L. Magnusson (eds.), The Open Method of Coordination in Action. The European Employment and Social Inclusion Strategies, Bruxelas, P.I.E. - Peter Lang S.A.: 415-445.

BOURDIEU, P. (1998), “Hoje a precariedade está em toda a parte”, in P. Bourdieu (ed.), Contrafogos, Oeiras, Celta Editora: 113-120. 
BOURDIEU, P. e Passeron, J. (1970), La Reproduction. Éléments pour une théorie du système d'einsegnement, Paris: Ed. de Minuit.

CENTENO, L. (coord.), Avaliação do Impacto da Estratégia Europeia de Emprego em Portugal - Políticas Ativas para a Empregabilidade, Lisboa: CIDES/DEPP.

COSTA, A. F. (2012), Desigualdades Sociais Contemporâneas, Lisboa, Editora Mundos Sociais.

DURKHEIM, E. (2007), De La Division Du Travail Social, Paris: P.U.F.

FERRERA, M. e SACCHI, S. (2005), "The Open Method of Coordination and National Institutional Capabilities. The Italian Experience”, in J. Zeitlin e P. Pochet (eds.), The Open Method of Coordination in Action. The European Employment and Social Inclusion Strategies, Brussels, P.I.E. - Peter Lang S.A.: 137-172.

FREYSSINET, J. (2007), El desafio de las políticas del empleo en el siglo XXI: La experiência reciente de los países de Europa occidental, Buenos Aires, Ceil-Piette Conicet.

GALLIE, D. (2004), “Unemployment, Marginalization Risks and Welfare Policy”, in D. Gallie (ed.), Resisting Marginalization. Unemployment Experience and Social Policy in the European Union, Oxford, Oxford University Press: 1-33.

HESPANHA, P. (2008), "Políticas Sociais: novas abordagens, novos desafios”, Revista de Ciências Sociais, 39 (1): 5-15.

HESPANHA, P. (2007), "The Activation Trend in the Portuguese Social Policy”, in A. S. Pascual e L. Magnusson (eds.), Reshaping Welfare States and Activation Regimes in Europe, Bruxelas, P.I.E. - Peter Lang s.d.: 207-240.

MAILAND, M. (2005), “The Involvement of Social Partners in Ative Labour Market Policy - do the patterns fit the expectations from regimes Theories?", in T. Bredgaard e F. Larsen (eds.), Employment policy from different angles, Copenhaga, DJOF Publishing Copenhagen: 135-151.

SERRANO PASCUAL, A. (2003), "Towards convergence of European activation policies?", in D. Foden e L. Magnusson (eds.), Five years' experience of the Luxembourg employment strategy, Bruxelas: ETUI: $141-162$

SILVA e PEREIRA (2012), “As Políticas de Proteção no Desemprego em Portugal”, Sociologia, Problemas e Práticas, 70: 133-150.

TILLY, C. (2005), "Historical perspetives on inequality", in M. Romero e E. Margolis (orgs.), The Blacwell Companion to Social Inequalities, Malden: Blackwell: 15-30.

VALADAS, C. (2012), A Europeização das Políticas de Emprego. Impactos e Implicações no Caso Português. Dissertação de Doutoramento, Universidade de Coimbra, Portugal.

VALADAS, C. (2011), "New challenges to a changing labour market and welfare system. The Portuguese recent experience". Sociologia On-line. 2 (disponível em: http://revista.aps.pt/cms/ files/artigos_pdf/ART4dc4180e7a121.pdf).

\section{NOTES}

1. Recorde-se que, apesar de a taxa de desemprego ter atingido níveis muito elevados, sobretudo, desde o ano de 2009, a subida do número de indivíduos desempregados foi constante e progressiva desde 2002. Para uma análise exaustiva da evolução do mercado de trabalho, da trajetória do desemprego em Portugal, das suas especificidades e implicações do ponto de vista 
das políticas públicas dirigidas aos desempregados, consultar dois trabalhos recentes da autora (Valadas 2012, 2011).

2. Isto levou à integração, em 2000, da EEE num plano político ambicioso conhecido como a Agenda de Lisboa, à qual se associa o ideal de construção da sociedade tecnologicamente mais avançada do mundo, com mais e melhores empregos e com mais coesão social.

3. Para uma sistematização de ideias a respeito da introdução e disseminação do conceito e dos princípios teóricos subjacentes às políticas ativas de emprego, consultar Barbier (2005).

4. Para além destes dois aspetos, os autores destacam a preocupação em torno do funcionamento (mais) eficiente dos serviços públicos de emprego.

5. Na perspetiva de Jacques Freyssinet (2007), as políticas ativas contemporâneas refletem, ainda que em proporções desiguais, duas tradições históricas distintas, uma influenciada pelo modelo sueco, suportada, designadamente, "pelos sindicatos da Europa ocidental quando reivindicam políticas ativas de emprego" e a outra de influência anglo-saxónica, ligada à disseminação da lógica do workfare (Freyssinet, 2007: 25).

6. A propósito das diferentes formas de entendermos as ideias e teorias, bem como a respetiva aplicação aos diferentes contextos nacionais, Iver Moller (2012) constitui uma referência bibliográfica importante.

7. Recordamos que, desde 2003, os PNE dos vários países foram integrados no PNR, o que determinou que os Estados-membros passassem a ter ainda mais autonomia para fixarem as prioridades das suas agendas políticas.

8. A combinação de ambas as vias metodológicas foi levada acabo num trabalho de investigação recente conduzido pela autora no âmbito da sua tese de doutoramento em Sociologia (Valadas, 2012).

9. De entre as iniciativas, anteriores à EEE, que combinavam medidas compensatórias com um certo grau de ativação, destacam-se os programas ocupacionais, existentes desde 1985 que visavam "através do envolvimento dos desempregados em atividades de utilidade social, valorizar as suas competências, mitigar os efeitos sociais negativos do desemprego e aumentar as suas possibilidades de reinserção no mercado de trabalho" (Portaria 192/96 de 30 de maio). Sobre esta questão, ver, entre outros, Centeno (2003) e Hespanha (2007).

10. De entre estes salientam-se a responsabilidade coletiva perante os riscos (e.g. de desemprego, doença) que o indivíduo enfrenta e que compete ao Estado, em certa medida, controlar, gerir, planificar.

11. Falamos, propositadamente, em "empregabilidade" e não em "emprego". O conceito de "empregabilidade" tem vindo a assumir um lugar de destaque no contexto da reforma das políticas do mercado de trabalho na UE e foi usado muito em particular no contexto da EEE. Tem subjacente a ideia de que os indivíduos são responsáveis pelo desenvolvimento das suas competências e pela manutenção e criação do seu próprio emprego.

12. A propósito da centralidade renovada atribuída ao conceito de "inserção" nas políticas sociais, cf. Hespanha (2008).

13. Cf. Resolução do Conselho de Ministros n.o 20/2012, disponível em: http://dre.pt/ pdf1sdip/2012/03/05000/0105901061.pdf [consultado em: 10-12-12].

14. Ao aumento, sem precedentes do desemprego, associa-se um aumento generalizado dos contrato precários e a ausência muito significativa de ofertas de emprego, tendo em conta a fortíssima contração no emprego no setor público e em certos ramos de atividade do setor privado, como é o caso do setor da construção e obras públicas.

15. Pensamos, por exemplo, nas possibilidades de criação de empregos no âmbito da "economia social", tendo em conta as necessidades sociais acrescidas que derivam do envelhecimento da sociedade portuguesa.

16. A propósito das alterações e restrições nos benefícios sociais concedidos aos desempregados, cf. Silva e Pereira (2012) e Valadas (2012). 
17. Chamamos-lhe assim, porque sendo esta a ideia propagandeada e difundida numa determinada fase da EEE, a sua concretização em Portugal lida, desde logo, com obstáculos relacionados com o funcionamento das instituições (e.g. ausência de trabalho em parceria, burocracia excessiva, baixa produtividade e dificuldade em gerir a discricionariedade por parte dos funcionários) e com a escassez de recursos financeiros, na medida em que a aposta na formação e na qualificação dos recursos humanos é onerosa e os seus efeitos dilatados no tempo. Dito de outro modo, estamos perante um bom exemplo da distância entre as ideias, os princípios e as orientações, definidos em termos teóricos, formais, e as práticas concretas, informais.

18. Aproximamo-nos da ideia de reprodução das desigualdades sociais cara a Pierre Bourdieu, em que a escola, designadamente, é vista como uma instituição reprodutora e legitimadora da cultura dominante (Bourdieu e Passeron, 1970). Sublinhe-se que esta forma de olhar as desigualdades sociais e, no fundo, de distinguir, numa análise mais fi na e qualitativa, os próprios sujeitos das aprendizagens, diverge de uma tendência recente no sentido da quantificação dos resultados, da condução das próprias políticas em função de imperativos estatísticos.

19. No fundo, de garantir as condições de emancipação que poderiam ser exploradas graças aos avanços científicos, à circulação da informação à escala mundial, etc..

\section{ABSTRACTS}

Neste artigo, propomo-nos analisar as mudanças que têm vindo a afetar as políticas públicas que, no domínio do emprego, têm sido desenvolvidas em Portugal ao longo da última década e meia. 0 texto que apresentamos constrói-se em torno de duas questões centrais: Num momento em que assistimos ao aumento sem precedentes do desemprego e à generalização das formas de emprego precárias, que configuração e quais as potencialidades reguladoras e emancipatórias das políticas de emprego prosseguidas pelo Estado português? Admitindo que o emprego é, por excelência, o fator de integração dos indivíduos na sociedade, em que medida a intervenção do Estado na promoção de emprego e no combate ao desemprego contribui para reduzir as desigualdades sociais e promover o bem-estar social?

In this article we analyse the changes that affect public employment policies in Portugal within the last fifteen years. We address two main questions: First, in times of growing, massive unemployment and increasing precarious jobs what is the shape of employment policies and which are they regulatory and emancipatory potentialities? Second, since having a job is the most important form of integration into society, how can the state intervene, through policies to combat unemployment and promote employment, to reduce social inequalities and promote social wellbeing?

Dans cet article, on analyse les changements qui marquent les politiques publiques de l'emploi au Portugal dans les quinze dernières années. L'article se construit autour de deux questions centrales: la première, dans un moment où on assiste a une augmentation progressive du chômage et de l'emploi précaire, quel devrait être la configuration des politiques de l'emploi et quel pourrait être son potentiel de régulation et d'émancipation? La seconde: si l'on considère que l'emploi est le facteur, de plus' important, d'intégration des individus dans la société, comment peuvent les politiques conduites par l'État - dirigées pour combattre le chômage et 
promouvoir l'emploi - aider à diminuer ou à éliminer les inégalités sociales et à garantir le bien être?

INDEX

Keywords: Unemployment, social inequality, employment, welfare state, ative policies

Palavras-chave: desemprego, desigualdades sociais, empregabilidade, Estado-Providência, políticas ativas

Mots-clés: chômage, inégalités sociales, emploi, État-providence, politiques actives

\section{AUTHOR}

CARLA VALADAS

Professora na Faculdade de Psicologia e Ciências da Educação, Universidade de Coimbra e na Escola Superior de Educação e Ciências Sociais, Instituto Politécnico de Leiria

csvaladas@gmail.com 